\title{
PRESENTATION-BASED LEARNING AND PEER EVALUATION TO ENHANCE ACTIVE LEARNING AND SELF-CONFIDENCE IN THE FINANCIAL MANAGEMENT CLASSROOM
}

\author{
${ }^{1}$ Bambang Sugeng \& Ani Wilujeng Suryani \\ Faculty of Economics, Universitas Negeri Malang, Indonesia
}

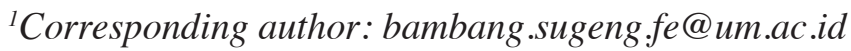

Received: 8 December 2017

Accepted: 6 May 2018

\section{ABSTRACT}

Purpose - The purpose of this study was to identify an effective learning strategy for students to engage authentically in their learning process. This study also aimed to introduce an innovative active learning approach to enhance students' involvement and to strengthen self-confidence throughout their learning in the Financial Management classroom. The approach involved the adoption of structured and accountable presentation-based learning activities.

Methodology - This study used action research design involving an iterative process of self-reflective cycles: planning, acting, observing and reflecting. The research was accomplished in two cycles. Three Financial Management classes of an undergraduate program consisting of 120 students in the first cycle and 110 students in the second cycle participated in this research as part of regular classroom activities. Semi-structured questionnaire, lecturer observation, and interviews were used as the method for data collection. The quantitative and qualitative data were analysed accordingly.

Findings - The results indicate that the approach adopted in this research reasonably enabled students to be actively engaged in their learning process and nullified free-riding learning behaviour among them. It also provided a chance for students to exercise their selfregulated learning towards becoming more independent learners and increased their confidence to speak and participate in class.

Significance - This research contributes to the improvement of teaching practices in higher education, particularly in Financial 
Management instruction. The results imply that providing some freedom for students to creatively design and be accountable for their own learning has great potential to enhance their authentic active learning and self-confidence.

Keywords: Active learning, self-confidence, peer-evaluation, presentation-based learning.

\section{INTRODUCTION}

Due to the main characteristics of accounting subject contents, being more technical and procedural, lecturers in Accounting classes tend to adopt a very mechanistic teaching practice. A lecturer commonly starts the class by explaining the conceptual aspects of the course topic, followed by examples or a demonstration of the concepts or procedures. Then, the lecturer ask the students to do some exercises. The session end by providing students with a formative test.

In a mechanistic teaching approach, the lecturers directly dominate the manner in which the students learn. This inhibits them from being involved in the creative learning activities. Student learning becomes considerably dependent on the lecturer because students are not invited to use and develop their cognitive and learning skills properly. Students seem to just reproduce and apply new information presented or made available by the lecturer while their engagement in the class is quite low (Doyle, 2008; Konopka, Adaime, \& Mosele, 2015).

Choy et al. (2015) examined the impact of cultural factors on students' awareness of their way of leaning and found that Asian students are inclined to depend on the teachers to get knowledge or information and are not interested to explore on their own. Students in such an environment would only be learning on the surface compared to deep learning.

The lack of student involvement in a deep learning approach seems to be related to the professional capacity of teachers in constructing a more rigorous instructional design (Malakolunthu \& Joshua, 2012). Schmidt et al. (2015) showed that the learning outcomes that result from such kind of learning is very limited. It does not effectively 
improve critical thinking and creative cognitive engagement of students. Such passive learning that widely occurs in accounting classes seems to affect student learning attitude and behaviour in other classes in the Accounting Department, one of which is the Financial Management class.

The dominant role of lecturers in student learning has commonly been found to lead students to become dependent learners and to lack learning confidence (Konopka et al., 2015). These students tend to develop negative perceptions toward the course (Tuncel, 2015). Some literature suggests that to alleviate such unproductive learning behaviour, enhancing student self-confidence becomes essentially important (Adelman \& Taylor, 2000; Hattie, 2002) because the level of self-confidence is related to their learning and achievement (Zins, Weiseberg, Wang, \& Walberg, 2004).

In this research, several lecturers attempted to enhance student learning activities through group discussion. The group was then requested to perform a presentation during our observation. It is evident and synonymous with Weimer (2013) that this kind of traditional form of discussion and presentation method is neither accountable nor well-structured.

Students, for example, often present their topic to the class only by reading the textbook. They focus their learning only on their group topic while they do not fairly pay attention to other course topics presented by other groups. This means that when students serve as an audience, they are not likely to have any fair learning experience whilst the classmates fulfil their presentation. Furthermore, in each group, which commonly consists of 6 or more students, there is often one or more group members who become free-riders. The free-riders (social loafers) do not share equal contribution towards a group project (Brooks \& Ammons, 2003). Their existence in the group have a negative impact on the group performance such as lowering the group's morale, productivity, and effectiveness and thus undermining the active learning process (Borjesson et al., 2006; Brooks \& Ammons, 2003; Ruel, Bastiaans, \& Nauta, 2003; Weimer, 2009). As educators, we may use a variety of creative methods to enhance students' learning activeness and at the same time their confidence in learning. In this study, we employ presentation-based learning activities to meet this goal whereby all student learning activities are built on prepared and conducted presentations by the 
students. The structured presentation could be achieved by utilizing computer-assisted presentation, i.e. power point, since this sort of application could guide the presentation to be conducted in a structured manner. The existing empirical studies mostly focused on investigating the impact of presentation with power point as a method of teaching; some are mentioned in Bartsch and Cobern (2003), El Khoury and Mattar (2012), Kosslyn et al. (2012) and Susskind (2005). In this study, power point presentation is used as the student's learning strategy, where it is the student who prepares and performs the presentation.

Accountable presentation, on the other hand, could be viewed from both presenting and audience students' perspectives. From presenting students, the accountable presentation will need students to prepare the presentation that meets the criteria of the audience students' interests in the presentation. Inversely, from audience students' perspective, the accountable presentation could be achieved by asking the audience to evaluate their peer-presentation. Some pedagogical advantages of this sort of presentation have been suggested to teach the students to listen and learn from others (Weimer, 2013). Shaw (2001) for example, suggests the following:

If the presenting student is held accountable for his or her performance by the audience, he or she would make an effort in researching an issue and presenting it in a clear, informative, and convincing way. If students in the audience are charged with the responsibility to evaluate each presentation, they are expected to listen and respond to the speakers with attention, critical comments, and judgmental decisions. (p. 140-141).

While the previous research on fostering student active learning and self-confidence through presentation (Briggs, 2014; Shaw, 2001; Tuncel, 2015) and peer evaluation (Baranowski \& Weir, 2011; Boud \& Molloy, 2013; Carless, 2007; Weimer, 2013) claim to be quite effective, the implementation of these kinds of learning approach in our context raises quite significant free-riding learning behaviour among students; hence active learning does not prevail in every individual student. The cultural aspect could be contributing to such learning behaviour (Choy et al., 2015).

Hence, this research contributes to the refinement of the learning approach suggested in the previous research. We develop a more structured and accountable presentation-based learning approach by 
embedding several significant improvements to the approach such as random appointment of students, individual assignment, and the use of power point media as a learning method instead of as a teaching method (Bartsch \& Cobern, 2003; El Khoury \& Mattar, 2012; Kosslyn et al., 2012; Susskind, 2005). Based on the above research background, this study intended to find a more authentic learning strategy that effectively enhances student active learning process and self-confidence. By implementing presentation-based learning activities, this study aims to improve current practices in a Financial Management class to ensure that creative, active, and self-regulated learning as well as self-confidence prevails among individual students and across course topics. More specifically, this study aims to answer the following questions.

i. How can free-riding behaviour that undermines active learning be minimized?

ii. How do students prepare and perform their presentation to promote their active learning?

iii. How do students feel about their presentation?

iv. How does peer-evaluation affect students' learning?

v. How is the students' self-confidence enhanced in their learning?

\section{LITERATURE REVIEW}

\section{Presentation and Active Learning}

Active learning, as an alternative to conventional teaching, engages students in educational strategies which allows them to acquire knowledge, skills, values and attitudes (Anastasiou \& Alves, 2004 cited in Konopka, Adaime, Mosele, 2015). Students are made to think critically or creatively, discuss the problem with a partner, in a small group, or with the entire class, express ideas through writing, provide and receive feedback, and reflect upon the learning process (Eison, 2010; Freeman et al., 2014). Therefore, active learning encompasses a various set of methods that commonly require students to perform significant proactive activities and take more responsibilities for various decisions associated with the learning endeavour (Hiemstra, 1999; Prince, 2004).

Among many strategies, presentation-based learning activities are regarded as the core method to build student's active learning. 
With this method students develop, organise, and present ideas and materials on a particular issue (Shaw, 2001). When students present and speak before the class, they are primarily practising some skills such as communication and arguing skills as well as building selfconfidence in speaking in the class forum. Students perceived that the presentation improved their understanding of the course content, taught them to research independently, and encouraged better class interactions and group learning (Ghorbani \& Ghazvini, 2016; Opitz $\& \mathrm{M}, 2010)$. Active involvement in a class could bring satisfaction and enjoyment which increase the retention rate and better grades (Allen \& Baughman, 2016).

Through presentation-based activities, active learning process occurs from the preparation phase to the presentation performance before the class. At the preparation phase, students are engaged in exploring material in various relevant references, browsing through the internet, discussing with friends or consulting with the lecturer, and preparing attractive and structured power point slides. Arguments by Grimm (2015) and Brown (2004) state that students learn concepts better and gain an in-depth understanding when they write about them. This also applies when students present the topic or content using the power point slides. Power point preparation requires students to thoroughly read and come up with the essential points of the content to be highlighted in the slides. The use of power point in the classroom overcomes the limitation of traditional lecturers because of the ability to structure, organise and emphasise key points efficiently (Apperson, Laws, \& Scepansky, 2008; Daniels, Kane, \& Rosario, 2007; Nouri \& Shahid, 2005, 2008; Szabo \& Hastings, 2000). Sugahara \& Boland (2006) reported that involving power point media in learning promotes better attention from learners to enable them achieve higher retention rate and encourage better participation rate.

\section{Accountable Presentation}

Accountable presentation-based learning activities are expected to encourage all students, either when acting as a presenter or as an audience, to be actively engaged in the learning process. When acting as a presenter, students will seriously prepare for their presentation since it will be assessed and responded by the audience. When serving as an audience, they would pay more attention so that 
they can provide a proper assessment to their peer presentations (Baranowski \& Weir, 2011; Shaw, 2001; Weimer, 2013). In this regard, students not only act as an audience but also contribute to the process so that it promotes the development of active autonomous learning whereby students think reflectively and take responsibility (Wen \& Tsai, 2006). Several studies reported that proactive peerevaluation in higher education helps students to adopt a more selfdirected attitude towards their learning and self-regulated learning that stimulate their learning process (Boud \& Molloy, 2013; Carless, 2007; Ion, Barrera-Corominas, \& Tomàs-Folch, 2016). For active engagement and responsibility of students in their own learning, peerassessment is very important (Gros, 2016). Shaw (2001) reported that students involved in a significant learning effort invested in presentation-based activities where they demonstrated interest in their performance and evaluated other's presentations.

\section{Presentation and Student's Self-confidence}

Self-confidence can be defined as how a student feels about him or herself and of his or her abilities in learning (Briggs, 2014; Salim, 2015). Students with self-confidence are more enthusiastic and persistent in their learning (Al-Hebaish, 2012; Pajares \& Miller, 1994; Zimmerman \& Kitsantas, 2005) because they pay more attention in class, get along better with their peers and have a more focused and inquisitive attitude (Miller, 2015). On the contrary, students with low self-confidence will most probably have negative feelings such as fear of failure, fear of humiliation, feeling inadequate and being anxious during the course delivery as well as towards the lecturer. They may refrain from speaking and actively participating in the classroom activities (Tuncel, 2015). Studies by Briggs (2014) and Tuncel (2015) confirmed a positive effect of self-confidence on students' achievements. Students with higher self-confidence were more successful than the ones with lower self-confidence. It is evident that self-confidence leads to a more positive outcome in the learning process. Briggs (2014) emphasises that self-confidence is a much better predictor of students' achievements than any other non-cognitive measure. To improve students' self-confidence, a teacher should encourage students to participate in class activities by providing them with an opportunity to speak and provide positive feedback (Tuncel, 2015). In our view, building students' self-confidence in learning cannot be separated from providing 
students with a learning opportunity to become an independent learner. Students with stronger self-confidence will tend to learn independently. In an independent learning environment, students have autonomy in deciding the learning direction and action, choosing learning resources, formulating problems, and reflecting on the outcome of that process, without negating a proper portion of lecturer's intervention (Healey, 2012; Pappas, 2013). If students are expected to develop independence in their learning, they need to be provided with the space to act as an autonomous and self-regulated learner (Rivera, 2012).

\section{METHODOLOGY}

This study was conducted in Financial Management classrooms in the Accounting Department. The aim of the Financial Management course is to enable students to have an understanding of basic concepts and analysis models and competence in applying them in corporate financial decision making contexts. In the Accounting Department, Financial Management course is commonly offered in the fifth of eight semesters set to accomplish undergraduate programs.

To achieve the objectives of this study, we applied a two cycleaction research design conducted in two semesters. Action research is a form of collective, self-reflective inquiry that participants in social situations undertake to improve the rationality and justice of their own social and educational practices and their understanding of these practices and the situations in which they carry out these practices (Kemmis \& McTaggart, 1990). Action research uses an iterative process and is generally thought to involve a spiral of selfreflective cycles of the following: planning, acting, observing and reflecting, re-planning, acting, observing again, reflecting again, and so on (Kemmis \& McTaggart, 1990; Kemmis \& Wilkinson, 1998). Three Financial Management classes of an undergraduate program consisting of 120 students in the first cycle and 110 students in the second cycle participated in this research as part of regular classroom activities. Semi-structured questionnaires and lecturer observation were used to collect student reflection and learning behaviour and other significant events that were revealed during the learning process. We also conducted interviews to confirm the data obtained from the two techniques. The data gathered was then analysed qualitatively and quantitatively depending on the data characteristic. 


\section{RESULTS AND DISCUSSION}

\section{First Cycle}

The first cycle of this study was conducted in the Financial Management classes of the first semester of the 2016/2017 academic year. This phase was mainly focused on identifying whether the teaching approach could alleviate free-riding behaviour so that every individual student will be involved actively in the learning process. As an element to improve the conventional group presentation, the students were placed into groups of four students (Heller \& Hollabough, 1992; Johnson, Johnson, \& Smith, 2006) and were asked to prepare power point slides for the topics assigned to each group which were to be presented in the class. Despite working in a group, each member of the group was individually asked to present to the class, a section of the topic prepared by the group that lasts about 20 to 30 minutes so that all the students of that semester would have the opportunity to contribute to this research.

The group was intentionally designed as a small group (wherein conventional design, a group commonly consists of more than six students). Each member of the group was required to be present, and this was intended to avoid free-riding, which mainly occurs in conventional group discussions. Semi-structured questionnaires on group performance (Brooks \& Ammons, 2003), were prepared with some modifications focusing on intra-group peer-evaluation. With this questionnaire, students' responses to a particular question was limited to some options, but we provided space for them to elaborate the option they chose. In this cycle, the instrument intended to find whether free-riding behaviour in group learning still existed; otherwise active learning process was expected to prevail in all students. Field notes (observation) were also used to record significant student learning-related events during the process.

The questionnaires were distributed only to group leaders and their responses were kept confidential from group members. They were asked to answer semi-structured questions about whether freeriding behaviour still existed among their group member and to provide feedback on the free-riding behaviour that was displayed. The group leader was intentionally chosen by the lecturer among students who showed above average learning performance. Table 1 shows the responses of group leaders who had indicated the number 
of free-riding participants within each group. A student is categorised as a free-rider if he or she shows 'no contribution at all' or 'very minimum contribution' to group work (Brooks \& Ammons, 2003).

Table 1

Responses to Free Rider Existence

\begin{tabular}{ccc}
\hline \multirow{2}{*}{$\begin{array}{c}\text { Number of free riders in } \\
\text { each group as claimed by } \\
\text { respondents }\end{array}$} & \multicolumn{2}{c}{ Respondents (group leader) } \\
\cline { 2 - 3 } 0 & 16 & Percentage \\
1 & 11 & 53 \\
2 & 3 & 33 \\
3 & 0 & 10 \\
Total respondent (group & $30 *$ ) & 0 \\
leaders) & & 100 \\
\hline
\end{tabular}

*) 120 students in three classes divided by 4 (each group consisting of 4 students)

Table 1 indicates that although the majority of respondents, i.e. 16 respondents $(53 \%)$ already claimed that there was no freeriding behaviour in the group, some of them (43\%) still found it to be apparent in their group work. Such free-riding behaviour was done mostly by one student among four members in each group as experienced by 11 groups (33\%) and by two students as experienced by 3 groups (10\%). They were also asked a question about how free-rider students performed in the group work and the reason for behaving as free-riders. Their responses are summarized in Table 2 .

\section{Table 2}

Free Rider Behaviour According to Respondents' Evaluation

\begin{tabular}{cl}
\hline Themes & \multicolumn{1}{c}{ Example of Respondents' Quotes } \\
\hline Unattendance & $\begin{array}{l}\text { She says that he has other important agenda so that he } \\
\text { is not able to come to group work conducted outside the } \\
\text { classroom. }\end{array}$
\end{tabular}

He always disappears when the group is working together to prepare the power point slides. 


\begin{tabular}{cl}
\hline Themes & \multicolumn{1}{c}{ Example of Respondents' Quotes } \\
\hline Disturbing & $\begin{array}{l}\text { The only he can do during hours of group working is keep } \\
\text { speaking out to group about irrelevant chats and is very } \\
\text { disturbing. }\end{array}$ \\
& $\begin{array}{l}\text { He is quite dominant in group but with unproductive } \\
\text { discourse. We'll be better without him. }\end{array}$ \\
Less confident & $\begin{array}{l}\text { In general, they suggest no ideas at all during we put together } \\
\text { working for presentation. They seem to be less confidence. }\end{array}$ \\
& $\begin{array}{l}\text { She got silent because she regards other members have a } \\
\text { better understanding on the topic than she does. }\end{array}$ \\
\hline
\end{tabular}

As shown in Table 2, the group leaders described the ways the freeriding students behaved in the group work under three modes, i.e., they did not attend the group work, their attendance in the group work was regarded as disturbing, and they did not feel like participating in the group work. Such behaviours led free-riding students to contribute nothing to the group work and thus, they were not involved in the active learning process. As also found by Weimer (2013), we noticed that when presenting the topic, the free-riders merely read the source book and the power slides, without explaining or elaborating. The free-riders were also found to be passive when they served as the audience. We observed that all such performances seem to stem from their lack of learning effort. Another unproductive performance also indicated the conventional classroom discussion method was still found in the first cycle of learning activities of this study. For example, students both individually and in the group tend to focus their learning only on their own presentation topic. They did not pay much attention to other topics which were presented by other groups. The reason why they showed such unproductive learning behaviour was quite surprising. Some students assumed that other topics were other groups' responsibility to prepare and to learn because they were the presenter of the topics. This assumption lead to the inactive level of student participation in the conventional classroom.

Thus we noted that presentation-based learning approach which was implemented in the first cycle of this study revealed some quantitative improvements. It had further enhanced the students' active learning compared to that of the conventional learning, where free-riding was wearing down active learning. 
The findings confirm that downsizing the number of members in each group led to minimising free-riding behaviour and thus enhancing individual student involvement in the learning process (Heller \& Hollabough,1992; Johnsonetal.,2006). Nevertheless,some weaknesses that were presented in the first cycle learning scenario, led to low student participation in the class discussion. This indicates that students needed to focus to perform more positive activities and perform responsibilities associated with the learning endeavour (Hiemstra, 1999; Prince, 2004).

Students also need to be propelled to perform more proactive activities and responsibility associated with the learning endeavour (Hiemstra, 1999; Prince, 2004). This strongly indicated that some improvements and redesigning were still needed to the scenario, which led to the second cycle action of this study.

\section{Second Cycle}

Similar to the first cycle, the second cycle of this study was also conducted on three Financial Management classes in the second semester of the 2016/2017 academic year. To respond to the first cycle results and to reduce free-riding behaviour that undermined active learning processes (Borjesson et al., 2006; Brooks \& Ammons, 2003; McArdle, Clements, \& Lendi, 2005; Ruel et al., 2003; Weimer, 2009), we decided to rearrange the presentation-based learning activities which were implemented in the first cycle. The rearrangement covered several slightly drastic changes to enhancine active learning and at the same time minimise as much as possible free-riding learning behaviour among the students. We assumed that there were some trade-offs between the significance of group work mechanism in learning and the assurance that all students would conduct active learning. There were at least four arrangements as the improvements of the scenarios which we had prepared for this purpose.

First, the presentation was to be done individually for all the topics which were selected from the course content compared to the first cycle where it was presented as group assignments. Consequently, all students needed to prepare and learn all topics for presentation. This measure was taken mainly to ensure that students no longer focussed their learning only on a particular topic as their presentation topic. Besides that, since students are individually responsible for their presentation (Gros, 2016; Wen \& Tsai, 2006), there will be no 
opportunity for them as individuals to behave as free-riding learners. The topic in a particular class session of the week was decided by the lecturer in advance.

The students had to individually prepare the topics for the presentation. Secondly, in order to support the initial arrangement, students were randomly appointed to present the topic during the class session.

This rule was to replace the arrangement of presentation turns among students which, in the first cycle was decided in advance based on the topic distribution among groups. This time around, for each particular class meeting, all individual students would be prepared to present. To maintain self-regulated learning, although this was an individual assignment, students could decide to work together through group learning outside the classroom to explore and comprehend the topic content. Students were also allowed to consult with the lecturer, if necessary, in preparing their presentations.

The third change of scenario was to involve the audience students in performing a peer-evaluation on their peers' presentations (Boud \& Molloy, 2013; Dochy, Segers, \& Sluijsmans, 1999; Gros, 2016; Shaw, 2001; Wen \& Tsai, 2006). This was different from the first cycle, where peer-evaluation was designed only to evaluate internal group learning performance. The measure was intended to ensure that all students serving as the audience, paid attention to all presentations conducted by their peers. To minimise the possible impact of this design, which could affect student self-confidence, we introduced a specific evaluation approach to student learning achievement. This resulted in the fourth change of scenario: student learning achievement was mainly assessed based on their participation in class discussion and learning efforts, and not merely on their performance in the final examination. Hence, the result of this evaluation was the major part of the final grade of the course. We also emphasised that if students' ideas, arguments, and explanation in participating in the class discussion and in conducting presentations were considered inaccurate, they would not be penalised. Conversely, if they were correct or accurate, the students would be awarded a grade point. As suggested by Tuncel (2015) we also provided some immediate positive feedback when they showed a positive performance. Hence, through this evaluation approach, students were expected not to hesitate to participate in class discussion actively and present their ideas and arguments which in turn, were expected to contribute to enhancing their learning confidence. 
Semi-structured questionnaires were distributed to all students to elicit their feedback on the way the learning approach was applied in the second cycle, which was expected to enhance active learning as well as promote students' self-confidence as indicated in the literature review (Healey, 2012; Pappas, 2013; Rivera, 2012; Tuncel, 2015). Table 3 summarises students' responses on the questionnaire.

As indicated in Table 3, students no longer had a chance to be freeriders. They were involved in the active learning process in various ways to prepare for their presentations. Most students (54\%) prepared their topic based on a single learning source which was a reference book recommended by the lecturer. They regarded that such a book is self-contained, meaning that the book already provided enough supporting materials for the topic. $46 \%$ of them actively referred to other sources, mainly involving browsing on the internet and still used the main source textbook. It was observed that students with multiple learning modes demonstrated an in-depth presentation and learning experience. This was evident as there were various elaborations and more current illustrations on the topic compared to the information available only in the primary source book.

\section{Table 3}

Students' Responses to the Questionnaire in the Second Cycle

\begin{tabular}{llc}
\hline \multicolumn{1}{c}{ Questions asked } & Themes in students' response & \% of response \\
\hline $\begin{array}{l}\text { How they prepare the } \\
\text { topic for presentation }\end{array}$ & $\begin{array}{l}\text { Based only on single source book as } \\
\text { recommended by the lecturer }\end{array}$ & 54 \\
& $\begin{array}{l}\text { Based on multiple sources including } \\
\text { browsing on the internet }\end{array}$ & 46 \\
\hline $\begin{array}{l}\text { How they learn to } \\
\text { understand the topic } \\
\text { content }\end{array}$ & Studying by themselves & 44 \\
\hline
\end{tabular}

Conducting a discussion with other 
Questions asked

Themes in students' response

$\%$ of response

How they overcome difficulties found in

Read the material repeatedly or asking

11 understanding the topic questions in the class discussion

Refer to other references/sources

including browsing on the internet

Discuss with other classmates

How preparation of

Helps to strengthen understanding the power point slides topic contributes to their learning

Helps to learn the topic content more

seriously

Taking much time

How peer-evaluation influences their learning performance
Very influential

The

presentation should be wellprepared so that it is highly graded

Getting nervous

Not influential

Whether or not being evaluated by a peer
How taking a role as an evaluator in peerevaluation influences their learning
Positive: learning harder, more responsible for their learning, increases self-confidence, strengthens retention and understanding, and learning public speaking

Negative: tiring, stressful, and feeling nervous

In striving to comprehend the topic, most students (56\%) chose to cooperate with classmates in the form of discussion conducted outside the classroom. Meanwhile, the rest of them (44\%) seemed to prefer to study alone as they had assumed that studying in a group was sometimes not productive and even disturbed their learning concentration. Nonetheless, discussion with other classmate was 
consistently more preferable (55\% of responses) for students when they dealt with some difficulties in understanding the topic. About a third of students tried to study alone and also referred to other sources such as browsing on the internet. The remaining students (11\%) chose to deal with the difficulties by reading the material repeatedly or bringing up the problems they encountered in the class discussion.

The students, who preferred to prepare individual presentations, were influenced by their solitary learning style. The followings are examples of statements from two students in the interviews:

"The effort I took to understand the topic materials to be presented was conducted through studying alone because I belong to one that feels more convenient when learning in quite a circumstance. When dealing with some difficulties, I tried to read more thoroughly and repeatedly the parts until I got some understanding of them."

"...to comprehend the course material for presentation, I used to study myself, tried to understand the topic by myself, tried to relate it to the material of other relevant subject matters, and concluded on the topic. I choose this strategy because I prefer learning in a silent environment without any disturbance from others."

In our observation, we noted that some students who preferred to study alone in accomplishing their individual assignment relatively showed a better performance in the presentation and also indicated higher self-confidence than those who worked cooperatively. This is understood that those with the former learning strategy have reasonably higher learning self-efficacy than those with the later strategy. Self-efficacy is also referred to as personal efficacy. This is a personal belief about the ability to perform a specific task in a given circumstance (Bandura, 1977). Students, who prefer to study on their own, to some extent, display their learning independence. This study has found support that a learning environment that fosters students' self-confidence is essential to enable them to become an independent learner (Healey, 2012; Pappas, 2013; Rivera, 2012; Tuncel, 2015). 
The students' responses to the first three questions indicate that although the presentation was an individual assignment, most students decided to work cooperatively with other classmates. Some also decided to make use of multiple learning sources creatively and were not merely dependent only on the reference determined by the lecturer. Internet becomes the preferable extra learning sources chosen by students compared to textbooks and other printed sources. This result to some extent indicates that by providing some freedom in their learning process, students will learn how to be responsible and creative in their own learning strategy and thus, learn to be an independent learner (Hiemstra, 1999; Prince, 2004).

Generally, the students responded positively when asked about the effectiveness of the power point preparation towards their life-long learning process. Almost all students in this study (97\%) suggested that preparing power point for class presentation helped strengthen their understanding of the topic. They also perceived that this form of assigment, urged students to be involved in deep and more serious learning. The results obviously provide support to arguments by Grimm (2015) and Brown (2004) that students will learn concepts better and gain in-depth understanding when they present them in power point. Students' responses are also consistent with several other findings such as Bartscha and Cobernb (2003) and Sugahara $\&$ Boland (2006). However, $7 \%$ of respondents considered this kind of assignment took too much time and that they had encountered learning overload. Although only a minority experienced this, the response could be understood especially among those students who were not familiar with presenting using the power point. For students, in general, identifying the critical points of the topic to be written into power point slides from course materials and designing the slides to be attractive for the class, seem to be conceptual, practical, and even to some extent artistic work that obviously takes time to create. In our observation, we noticed that students with higher academic performance wrote only the key points of topic material into their power point slides. They then continued to explain and elaborate on the slides to the class. On the other hand, those with lower academic performance seemed only to copy and paste the topic material into their slides, and they then presented them by merely reading from the slides without any explanation.

Students' active learning was also expected to be triggered by their peer-evaluation. Students' response on how this peer-evaluation 
affected their learning performance was quite varied. Most of them $(69 \%)$ suggested that such evaluation was very influential as they had to embrace a deeper approach to learning to be better prepared in order to gain a higher grade from their peers. Nevertheless, about $7 \%$ of students complained that the evaluation caused them to be nervous before the class. This result confirms that peer-evaluation encourages most students to increase their learning efforts toward their better learning achievement (Boud \& Molloy, 2013; Carless, 2007; Gros, 2016). However, some students (24\%) surprisingly felt that peer-evaluation was not influential at all. They were of the opinion that they needed to be better prepared whether or not they were to be evaluated by their peers. In our view, this kind of attitude represents positive learning values. It reflects their sense of responsibility for their own learning to meet the interest of others such as enabling their classmates to easily understand the topic that was being presented.

When taking the role as evaluator of their peers, almost half of the students (46\%) suggested that their peers' presentation was treated as a reference to prepare a better presentation of their own. This means that when serving as an evaluator, students use peers' presentations as means to reflect and learned for preparing a better individual performance. This result confirms the views that peerevaluation could serve as an instrument to enable the student to be a reflective, self-directed, and autonomous learner (Ion et al., 2016; Wen \& Tsai, 2006) which is very beneficial for developing better student learning processes. Moreover, about 39\% of students claimed that serving as peer evaluator seriously encouraged them to follow the presentation conducted by other students, as indicated by Baranowski and Weir (2011), although some other students (11\%) suggested that this provided experience to evaluate other peoples' performance. Students' responses further elaborated on power point preparation and peer-evaluation as properties of structured and accountable presentation which provided evidence that the approach undoubtedly contributed to enhancing active student learning, and thus, overcoming the limitations of the conventional class discussion practices in our institution.

It has been indicated in the empirical literature that encouraging students to act and speak through presentation and discussion and giving them positive feedback instantly can improve their self- 
confidence (Tuncel, 2015). Most of the student responses (93\%) indicated that the presentation-based learning approach implemented in this study enabled them to enhance their learning self-confidence. When students were asked further on how the approach could increase their self-confidence, their responses revealed two reasons. First, they were getting confident since they felt well-prepared for class presentation as the result of their more intense learning efforts. Second, their confidence may have reached a higher level as the learning approach enabled them to be more familiar with, and to speak confidently about the topic. Although the learning scenario implemented in this study is favouring active learning and selfconfidence enhancement (see for example Allen \& Baughman, 2016; Brown, 2004; Ghorbani \& Ghazvini, 2016; Grimm, 2015; Opitz \& M, 2010; Shaw, 2001; Tuncel, 2015), it does not mean that the approach is without any limitations or negative outcomes. $7 \%$ of the responses to this question showed that they felt unhappy with the approach. They claimed that they were getting stressed and nervous, working with the approach. This indication is obviously worrying as it could result in boss of self-confidence. Therefore, it is imminent that the lecturer treats such students differently to help them to learn more naturally.

Participants' reflections, on the overall learning approach were obtained by asking them to figure out both positive and negative outcomes of the approach. In general, they were consistent with their responses to previous questions. Over three quarters of students (see Table 3) described that the learning approach provided a positive learning environment that enabled them to learn effectively, be more responsible for their own learning, in addition to increasing self-confidence, strengthening retention and understanding course material, as predicted by Allen and Baughman (2016). They also learned public speaking. The following quotations from three students in the interviews represent a positive appreciation to the learning approach.

...presentation rules in Financial Management class obviously give some learning advantages to me mainly as a result of learning efforts induced by the rules. It enables me to not only understand the underlying concepts in the topics but also importantly helps to keep such understanding in mind. 
I have learned from working with the individual assignment on how to be responsible for my own learning although it was very hard to deal with at the outset.

To me the scenario was very positive. I am fond of the teaching method employed by the lecturer. Since the presentation would be conducted individually through random appointment, each student should be prepared all the time and understand the material in detail. This is a very beneficial learning assignment and is motivating me to consistently read and learn the topic material before every single class session begins.

On the other hand $23 \%$ of the students indicated that learning in this scenario was mainly tiring and stressful. For some students, preparing power point slides was time-consuming. As an example, one student stated in the interview as follows:

...I often spent until late night to work with my presentation slides as I have to work with plenty of course material and time restriction for the next morning class session. It was tiring and burdensome since I also got work for other subject assignments to accomplish.

During the second cycle process, other evidence was also elicited from the observation of the lecturer. As predicted, there was a significant increase in the number of students who actively participated in the class discussion. The class discussion was no longer dominated only by a few students who had above average academic performance, as found in the conventional discussion method. Interestingly, the class also involved newcomers which generally consisted of students with introvert learning styles. The way they participated varied in quality, from simple "what and how-questions" as generally posed by newcomers, to more complex contributions such as arguing one's statements and presenting richer and complex elaboration on the issue which was being addressed. As the class went on to the following weeks, more and more students contributed to the class discussion, and more students were getting familiar with participating. We noted that such improvements were achieved as a result of the rules embedded in the learning scenario that forced each student to prepare for each topic. Surprisingly, the assessment mechanism 
which emphasized heavily on the participation performance of students instead of solely depending on final examination, seemed to have had a direct triggering effect on enhancing active student participation. As stated by one student:

The evaluation weight which is given more on class participation strongly encourages me to prepare the topic for enabling to take part in active contribution in class discussion, for me to obtain a reasonably higher grade.

Unique behaviours were also observed during the second phase of classroom activities. Initially, quite a lot of students looked stressed while waiting for the random appointment by the lecturer to carry out presentation. Due to this the male students chose not to be present for the class meetings where the presentation was to be initiated. As they were not present for the presentation initiation session, they were unprepared. In contrast, several students even looked cheerful expecting to be appointed for presentation. To accommodate such students' eagerness, we decided to always begin the class by offering an opportunity for one or two students to voluntarily undertake the presentation, after which random appointment was then employed. Other interesting behaviours reported in Shaw (2001) were also evident in this study, such as some students making professionallike presentations, for instance, by conveying opening and closing greetings as well as greeting gestures to the audience. Even as they were presenting, some of them showed lecturer-style by asking their peers (audience) some relevant questions.

\section{CONCLUSION}

The Conventional presentation-based learning approach in our Financial Management class needed to be revised since, in our context, the approach was not able to effectively increase the active learning process among students. By embedding several significant improvements to the approach as suggested in the literature, we developed more structured and accountable presentation-based learning activities. The results of this study indicate that this learning approach was able to enhance the active learning process and ensure that all individual students in the class were involved in the process. Besides neutralising free-riding behaviour among students, the approach enabled students to learn to be independent learners by 
providing them space to decide on their own learning strategies. In addition to these, it was also evident that the approach increased students' self-confidence as they were involved in their own intense learning process and could to effectively participate and contribute in the class forum. However, the approach, to some extent, caused student learning to be overloaded and this was its key shortcoming. Therefore, it is recommended that for future implementation of this strategy in Financial Management class, the course topics to be assigned should be chosen more selectively so that the load of student learning is manageable. Alternatively, since students' response also suggested that the strategy enables them to strengthen and retain their understanding of the materials, future research on this issue should to further examine the effectiveness of the strategy in increasing students' cognitive achievements.

\section{ACKNOWLEDGMENT}

We would like to aknowledge the Dean of Faculty of Economics developing a favorable academic climate in the faculty that enables lecturers to conduct classroom action research for reflective teaching as part of continuous professional improvement.

\section{REFERENCES}

Adelman, H., \& Taylor, L. (2000). Looking at school health and school reform policy through the lens of addressing barriers to learning. Children Services: Social Policy, Research and Practice, 3, 117-132.

Al-Hebaish, S. M. (2012). The correlation between general selfconfidence and academic achievement in the oral presentation course. Theory and Practice in Language Studies, 2(1), 6065.

Allen, P. J., \& Baughman, F. D. (2016). Active learning in research methods classes is associated with higher knowledge and confidence, though not evaluations or satisfaction. Frontiers in Psychology, 7(279), 1-7. https://doi.org/10.3389/ fpsyg.2016.00279

Apperson, J. M., Laws, E. L., \& Scepansky, J. A. (2008). An assessment of student preferences for power point presentation 
structure in undergraduate courses. Computers \& Education, $50,148-153$.

Bandura, A. (1977). Self-efficacy: Toward a unifying theory of behavioral change. Self-Efficacy: Toward a Unifying Theory of Behavioral Change, 84(2), 191-215.

Baranowski, M., \& Weir, K. (2011). Peer evaluation in the political science classroom. Political Science and Politics, 44(4), 805811. https://doi.org/10.1017/S1049096511001302

Bartsch, R.A., \& Cobern, K. M. (2003). Effectiveness of PowerPoint presentations in lectures. Computers and Education, 41(1), 77-86. https://doi.org/10.1016/S0360-1315(03)00027-7

Borjesson, P. O., Hamidian, A., Kubilinskas, E., Richter, U., Weyns, K., \& Odling,P.(2006). Free-riding in group work - mechanisms and countermeasures. Retrieved from https://www.lth.se/ fileadmin/lth/genombrottet/konferens2006/p_o_b_rjesson_ mfl.pdf /

Boud, D., \& Molloy, E. (2013). Rethinking models of feedback for learning: the challenge of design. Assessment and Evaluation in Higher Education, 38(6), 689-712.

Briggs, S. (2014). Why self-esteem hurts learning but selfconfidence does the opposite. Retrieved February 18, 2017, from https://www.opencolleges.edu.au/ informed/?s=Why+Self-Esteem+Hurts+Learning+But+SelfConfidence+Does+The+Opposite

Brooks, C. L., \& Ammons, J. L. (2003). Free-riding in group projects and the effects of timing, frequency, and specificity of criteria in peer assessments. Journal of Education for Business, 78, 268-272.

Brown, K. (2004). Technology: building interaction. TechTrends: Linking Research and Practice to Improve Learning, 48(5), 36-38.

Carless, D. (2007). Learning-oriented assessment: conceptual bases and practical implications. Innovations in Education and Teaching International, 4(1), 57-66.

Choy, S. C., Sedhu, D. S., Liew, Y. L., Lee, M. Y., Malenee, A., \& Anuar, N. (2015). Influence of culture on students' awareness of how and why they learn. Malaysian Journal of Learning and Instruction, 12, 49-67.

Daniels, L., Kane, J., \& Rosario, B. (2007). The impact of PowerPoint on student performance, course evaluations, and 
student preferences in economic courses: An experiment at three institutions. Chicago. Retrieved from http://economic. oswego.edu/papers/ASSA007.pdf

Dochy, F., Segers, M., \& Sluijsmans, D. (1999). The use of self-, peer and co-assessment in higher education: A review. Studies in Higher Education, 24(3), 331-350. https://doi.org/10.1080/ 03075079912331379935

Doyle, T. (2008). Helping students learn in a learner-centered environment: a guide to facilitating learning in higher education (10th ed.). USA: Stylus Publishing, LLC.

Eison, J. (2010). Using active learning instructional strategies to create excitement and enhance learning. Retrieved from https://www.cte.cornell.edu/documents/presentations/Active Learning - Creating Excitement in the Classroom - Handout. pdf

El Khoury, R. M., \& Mattar, D. M. (2012). PowerPoint in accounting classrooms: Constructive or destructive? International Journal of Business and Social Science, 3(10), 240-259. Retrieved from http://www.ijbssnet.com

Freeman, S., Eddy, S. L., Mcdonough, M., Smith, M. K., Okoroafor, N., Jordt, H., \& Wenderoth, M. P. (2014). Active learning increases students' performance in science, engineering, and mathematics. Proceedings of the National Academy of Sciences of the United States of America, 111(23), 8410-8415.

Ghorbani, A., \& Ghazvini, K. (2016). Using paper presentation breaks during didactic lectures improves learning of physiology in undergraduate students. Advances in Physiology Education, 40(1), 93-97.

Grimm, S.D. (2015).Learning Logs: Incorporating Writing-to-Learn Assignments into Accounting Courses. Issues in Accounting Education, 30(2), 79-104.

Gros, B. (2016). The design of smart educational environments. Smart Learning Environments, 3(15), 1-11.

Hattie, J. (2002). What are the attributes of excellent teachers? Retrieved from https://cdn.auckland.ac.nz/assets/education/ hattie/docs/teachers-make-a-difference-ACER-(2003).pdf

Healey, M. (2012). Developing independent \& autonomous learning. Retrieved from https://www.mickhealey.co.uk/workshopsoffered/active-independent-and-inclusive-learning/ developing-independent-and-autonomous-learning 
Heller, P., \& Hollabough, M. (1992). Teaching problem solving through cooperative grouping. Part 2: Designing problems and structuring groups. American Journal of Physics, 60(7), 637-644.

Hiemstra, R. (1999). Self-directed learning. In The Sourcebook for Self-Directed Learning (1st ed., pp. 9-20). Amherst: HRD Press, Inc.

Ion, G., Barrera-Corominas, A., \& Tomàs-Folch, M. (2016). Written peer-feedback to enhance students' current and future learning. International Journal of Educational Technology in Higher Education, 13(15), 1-11. https://doi.org/10.1186/s41239-0160017-y

Johnson, D. W., Johnson, R. T., \& Smith, K. A. (2006). Active learning: Cooperation in the university classroom. Interaction (3rd ed.). Edina, MN.

Kemmis, S., \& McTaggart, R. (1990). The Action Research Planner (3rd ed.). Geelong, Melbourne: Deakin University Press.

Kemmis, S., \& Wilkinson, M. (1998). Participatory action research and the study of practice. In B. Atweh, S . Kemmis \& P. Weeks (Eds). In Action Research in Practice. London: Routledge.

Konopka, C. L., Adaime, M. B., \& Mosele, P. H. (2015). Active teaching and learning methodologies: Some considerations. Creative Education, 6(14), 1536-1545.https://doi.org/10.4236/ ce.2015.614154

Kosslyn,S.M., Kievit,R.A.,Russell,A.G., \& Shephard,J.M.(2012). Powerpoint presentation flaws and failures: A psychological analysis. Frontiers in Psychology, 3(230), 1-22.

Malakolunthu, S., \& Joshua, A. (2012). Learning approaches of undergraduate computer technology students: Strategies for improvement. Malaysian Journal of Learning and Instruction, 9, 1-14.

McArdle, G., Clements, K. D., \& Lendi, K. H. (2005). The free-rider and cooperative learning groups: Perspectives from faculty members. Retrieved from http://files.eric.ed.gov/fulltext/ ED492459.pdf/

Miller,A. (2015). How to build a student's self confidence. Retrieved from https://www.livestrong.com/article/188430-how-tobuild-a-students-self-confidence/

Nouri,H., \& Shahid,A.(2005). The effect of powerpoint presentations on student learning and attitudes. Global Perspectives on Accounting Education, 2, 53-73. Retrieved from http:// citeseerx.ist.psu.edu/viewdoc/download?doi=10.1.1.214.3178 $\&$ rep $=$ rep $1 \&$ type $=$ pdf 
Nouri, H., \& Shahid, A. (2008). The effects of powerpoint lecture notes on student performance and attitudes. The Accounting Educators' Journal, 18, 103-117.

Opitz, H. S. B., \& M, T. (2010). Student perceptions of the use of presentations as a method of learning endocrine and gastrointestinal pathophysiology. Advances in Physiology Education, 34(2), 7585. https://doi.org/10.1152/advan.00105.2009

Pajares, F., \& Miller, M. D. (1994). Role of self-efficacy and selfconcept beliefs in mathematical problem solving: A path analysis. Journal of Educational Psychology, 86(2), 193-203.

Pappas, C. (2013). 8 important characteristics of adult learners. Retrieved from https://elearningindustry.com/8-importantcharacteristics-of-adult-learners

Prince, M. (2004). Does active learning work? A review of the research. Journal of Engineering Education, 93(3), 223-232. https://doi.org/10.1002/j.2168-9830.2004.tb00809.x

Rivera, A. (2012). Active learning. Retrieved from https://www. slideshare.net/ariveera18/active-learning-powerpointpresentation/

Ruel, G. C., Bastiaans, N., \& Nauta, A. (2003). Free-riding and team performance in project education. Retrieved from http://www. rug.nl/research/portal/files/3010481/03a42.pdf/

Salim, A. (2015). General self-confidence and its implication on students' achievement in oral presentation. Journal of English Education and Linguistic Studies, 2(2), 34-48. Retrieved from http://jurnal.stainkediri.ac.id/index.php/jeels/article/ view/95/97

Schmidt, H. G., Wagener, S. L., Smeets, G. A. C. M., Keemink, L. M., \& Molen, H. T. van der. (2015). On the use and misuse of lectures in higher education. Health Professions Education, 1(1), 12-18. Retrieved from https://www.sciencedirect.com/ science/article/pii/S2452301115000115

Shaw, V. N. (2001). Training in presentation skills: An innovative method for college instruction'. Education, 122(1), 140-144.

Sugahara, S., \& Boland, G. (2006). The effectiveness of powerpoint presentations in the accounting classroom. Accounting Education, 15(4), 391-403.

Susskind, J. E. (2005). Powerpoint's power in the classroom: Enhancing students' self-efficacy and attitudes. Computers and Education 2, 45(2), 203-215. 
Szabo, A., \& Hastings, N. (2000). Using IT in the undergraduate classroom: Should we replace the blackboard with powerpoint? Computers and Education, 35(3), 175-187.

Tuncel, H. (2015). The relationship between self-confidence and learning Turkish as a foreign language. Educational Research and Reviews, 10(18), 2575-2589. https://doi.org/10.5897/ ERR2015.2445

Weimer, M. (2009). Dealing with free-riders. Retrieved from http://www.facultyfocus.com/ articles/teaching-and-learning/ dealing-with-free-riders/

Weimer, M. (2013). Student presentations: Do they benefit those who listen? Retrieved from https://www.facultyfocus.com/ articles/teaching-and-learning/student-presentations-do-theybenefit-those-who-listen/

Wen, M. L., \& Tsai, C.-C. (2006). University Students' Perceptions of and Attitudes Toward (Online) Peer Assessment. Higher Education, 51(1), 27-44. https://doi.org/10.1007/s10734-004$6375-8$

Zimmerman, B. J., \& Kitsantas, A. (2005). Homework practices and academic achievement: The mediating role of selfefficacy and perceived responsibility beliefs. Contemporary Educational Psychology, 30, 397-417. https://doi.org/10.1016/j. cedpsych.2005.05.003

Zins, J. E., Weiseberg, R. P., Wang, M. C., \& Walberg, H. J. (2004). Building academic success on social and emotional learning: What does the research say? New York: Teacher College, Columbia University. 